\title{
Article
}

\section{Growth, functional capacities and motivation for achievement and competitiveness in youth basketball: An interdisciplinary approach}

Carvalho, H.M., Gonçalves, C.E., Collins, D., and Paes, R.R.

Available at http://clok.uclan.ac.uk/18456/

Carvalho, H.M., Gonçalves, C.E., Collins, D., ORCID: 0000-0002-7601-0454 and Paes, R.R. (2018) Growth, functional capacities and motivation for achievement and competitiveness in youth basketball: An interdisciplinary approach. Journal of Sports Sciences, 36 (7). pp. 742-748. ISSN 0264-0414

It is advisable to refer to the publisher's version if you intend to cite from the work. http://dx.doi.org/10.1080/02640414.2017.1340654

For more information about UCLan's research in this area go to http://www.uclan.ac.uk/researchgroups/ and search for <name of research Group>.

For information about Research generally at UCLan please go to http://www.uclan.ac.uk/research/

All outputs in CLoK are protected by Intellectual Property Rights law, including Copyright law. Copyright, IPR and Moral Rights for the works on this site are retained by the individual authors and/or other copyright owners. Terms and conditions for use of this material are defined in the policies page. 
Growth, functional capacities and motivation for achievement and competitiveness in youth basketball: an interdisciplinary approach

HUMBERTO M CARVALHO ${ }^{1}$, CARLOS E GONÇALVES ${ }^{2}$, DAVE COLLINS ${ }^{3}$, ROBERTO R PAES ${ }^{1}$

${ }^{1}$ Faculty Physical Education, University of Campinas (UNICAMP), Campinas/São Paulo, Brazil; ${ }^{2}$ Faculty of Sports Sciences and Physical Education, University of Coimbra, Coimbra, Portugal; ${ }^{3}$ Institute for Coaching and Performance, University of Central Lancashire, Preston, UK

\section{Corresponding author:}

Humberto Moreira Carvalho

Faculdade de Educação Física

Av. Érico Veríssimo 701, Barão Geraldo, 13083851 Campinas - SP, BRASIL

E-mail: hmoreiracarvalho@gmail.com 


\section{Abstract}

The interaction of multiple influences on the path to sport success is not yet fully understood by sport scientists. In this study, we examined variation in body size, functional capacities and motivation for achievement, competitiveness and deliberate practice of youth basketball players associated with differences in biological maturity status and chronological age. Reflecting the importance of interactive effects, we examined the relationships between the psychological variables and functional capacities. Fifty-eight male basketball players aged 9.5 to 15.5 years were considered. Variables included chronological age, estimated age at PHV, stature, body mass and sitting height by anthropometry; the Work and Family Orientation and Deliberate Practice Motivation Questionnaires were also used. Finally, the Line Drill test and Yo-Yo Intermittent Recovery level 1 (Yo-Yo IR1) tests were used as functional capacities indicators for basketball. Variance components models derived from series of multilevel linear regression models revealed a significant variation by maturity status for body size, functional capacities indicators, mastery and will to excel. The influence of estimated maturity status on mastery and will to excel was independent of chronological age. Furthermore, after controlling for age, an influence of estimated maturity on competitiveness was apparent. In contrast, no relationships were observed between psychological variables and functional capacities indicators. We conclude that growthrelated changes are relevant to understanding players' motivations for achievement, competitiveness and deliberate practice. This should be of interest to those involved in the selection and development of youth basketball players.

Keywords: youth athletes, basketball, growth, maturation 


\section{INTRODUCTION}

Talent identification, selection and development in sport are complex problems (Abbott, Button, Pepping, \& Collins, 2005) that are of great interest for sport science researchers, coaches, sport governing bodies and, ultimately, young athletes. Adolescent athletes, often labelled as "elite" or "talented" at early ages, are frequently subject to a very structured selection process and consequently, especially within a single sport, are often relatively homogeneous in functional capacity and sport-specific skills (Malina, 1994). Interestingly, this homogeneity is often apparent with relatively different patterns of training experience (Diogo \& Goncalves, 2014). Such issues notwithstanding, the role of physical growth and functional performance in team sports tends to be overestimated in the selection process, where late maturing boys may be systematically excluded in favour of average and early maturing boys as chronological age and sport specialization increase (Bergeron et al., 2015; Gonçalves, Rama, \& Figueiredo, 2012). In youth basketball particularly, body size and sport-specific functional capacities are influenced by biological maturation (Carvalho, Silva, Eisenmann, \& Malina, 2013; Carvalho, Silva, Figueiredo, Goncalves, Philippaerts, et al., 2011); thus, this exclusion may be understandable.

In contrast perhaps we know that talent identification, selection and development require a multidisciplinary approach (Reilly, Williams, Nevill, \& Franks, 2000). Nevertheless, researchers rarely adopt holistic approaches and instead, consider unidisciplinary perspectives from either biological, psychological or behavioural variables; a clearly flawed approach. For instance, even if some young players have certain physical or anthropometric qualities that place them at an early stature advantage in basketball, they must also have the desire and motivation to train at high levels (as well as other appropriate characteristics) to realise their potential (Bailey et al., 2010; Baker \& Horton, 
2004). As such, one-dimensional snapshots may fail to capture the capacity for those processes athletes must satisfy to eventually achieve excellence. Accordingly, understanding young athletes' beliefs, perceptions and motives underpinning participation in sport contexts influenced by the deliberate practice model (Gonçalves et al., 2012; Gonçalves, Silva, Carvalho, \& Goncalves, 2011) needs to adopt a multifactorial approach.

Physiological, psychological, social and behavioural changes characterize adolescence (Sherar, Cumming, Eisenmann, Baxter-Jones, \& Malina, 2010). It has been suggested that psychological characteristics play a central role in the development of sport expertise (Baker \& Horton, 2004). Limited observations based in interdisciplinary approaches indicate a relevant role of motivation to distinguish young athletes classified has elite and sub-elite (Elferink-Gemser, Visscher, Lemmink, \& Mulder, 2007; ElferinkGemser, Visscher, Lemmink, \& Mulder, 2004). Just as changes during pubertal growth have an influence on functional performance, it is likely that psychological and behavioural characteristics will also be impacted by maturity status. Interpretation of the interactions between body dimensions, functional capacities and psychological characteristics needs to consider appropriate analytical approaches. Thus, in this study we examined variation in body size, functional capacities and motivation for achievement, competitiveness and deliberate practice of youth basketball players associated with differences in biological maturity status and chronological age, adopting a multilevel modelling framework. Also, we examined the interactions of motivation for achievement, competitiveness and deliberate practice with functional capacities, considering allometric modelling to partition the influence of body dimensions on functional capacities.

\section{METHOD}




\section{Participants}

The sample included 58 male basketball players, 9.5 to 15.5 years. The players were engaged in formal training and competition within a local club from the Campinas metropolitan region and competed in state level supervised by the Federação Paulista de Basketball (FPB). The study was approved by the Research Ethics Committee of the University of Campinas. and was conducted in accordance with recognized ethical standards (Harriss \& Atkinson, 2009). Participants were informed about the nature of the study, that participation was voluntary and that they could withdraw from the study at any time. Players and their parents or legal guardians provided informed written consent.

\section{Instrumentation and Procedure}

\section{Anthropometry}

All measurements were taken by a single experienced observer following standardized procedures (Lohman, Roche, \& Martorell, 1988). Reliability estimates for the observer are published elsewhere (Carvalho, Silva, Figueiredo, Goncalves, Castagna, et al., 2011; Carvalho, Silva, Figueiredo, Goncalves, Philippaerts, et al., 2011). Stature and sitting height were measured with a portable stadiometer (Seca model 206, Hanover, MD, USA) to the nearest $0.1 \mathrm{~cm}$. Leg (subischial) length was estimated as stature minus sitting height. Body mass (BM) was measured with a calibrated portable balance (Seca model 770, Hanover, MD, USA) to the nearest $0.1 \mathrm{~kg}$.

\section{Maturity status}

Chronological age was calculated to the nearest 0.1 year by subtracting birth date from date of testing. Age at peak height velocity (PHV) was estimated with the maturity offset protocol (Mirwald, Baxter-Jones, Bailey, \& Beunen, 2002). The protocol predicts time before or after PHV based on chronological age, stature, body mass, sitting height and 
estimated leg length (stature minus sitting height). Based on maturity offset, the participants, ranging from -2.96 to +2.45 years from/to $\mathrm{PHV}$, were grouped into three maturity status categories for analysis: pre-PHV (PHV $\leq-1.00$ year; $\mathrm{n}=25$ ), mid-PHV $(-1.00<$ PHV $<+1.00$ year; $\mathrm{n}=18)$, and post-PHV $(\mathrm{PHV} \geq+1.00 ; \mathrm{n}=15)$.

\section{Functional performance}

Two protocols were used as measures of functional capacity for basketball: a short-term maximal effort protocol, the Line Drill test (Carvalho, Silva, Figueiredo, Goncalves, Castagna, et al., 2011; Semenick, 1990) and an intermittent endurance test, the Yo-Yo Intermittent Recovery level 1 test (Yo-Yo IR1) (Bangsbo, 1994).

In the Line Drill protocol, players ran $140 \mathrm{~m}$ as fast as possible in the form of four consecutive shuttle sprints of 5.8, 14.0, 22.2 and $28.0 \mathrm{~m}$ within a regulation basketball court. Athletes began the test 1-m behind the baseline of the basketball court, where a video recorder (recording rate of $120 \mathrm{fps}$ ) aligned with the baseline (Sony, Tokyo, Japan) was used as reference for the beginning and end of the test. Time was recorded by video analysis of players crossing the reference baseline with available video analysis software Kinovea - 0.8.15 (http://www.kinovea.org). Verbal encouragement for an all-out effort was given throughout the test. Reliability of video recording for time measurement was completed by comparison with photoelectric cells. Twenty-five time recordings at the reference baseline from a regular basketball court were made simultaneously, using a gate of photoelectric cells (Speed Test 6.0 Standard, Cefise, Nova Odessa - SP, Brazil) and a video recorder. Agreement between methods showed no systematic or proportional bias (calibration equation: $Y=0.034+0.997 \cdot X$ ), with a technical error of measurement 0.12 s $(95 \%$ confidence interval 0.10 a 0.17$)$ and a perfect correlation between methods. Thus, video analysis for time recording in the Line Drill test was assumed to be reliable and accurate. 
The Yo-Yo IR1 was performed by all participants (Bangsbo, 1994). The protocol is based on repeated $2 \times 20-\mathrm{m}$ runs back and forth between the starting, turning, and finishing line at a progressively increased speed controlled by audio bleeps from a tape recorder (Bangsbo, 1994). The athletes have a 10-s active rest period between each bout, jogging in a distance of $2 \times 5-\mathrm{m}$. Players ran until they were no longer able to maintain the required speed; the test was completed when athletes failed twice to reach the finishing line in time. Covered distance was considered in meters.

Motivation for achievement, competitiveness and deliberate practice questionnaires Participants were required to complete the two questionnaires before practice sessions, in the presence of one of the researchers. The Work and Family Orientation Questionnaire (WOFO - (Spence \& Helmreich, 1983) has 19 items and assesses four dimensions of achievement: personal unconcern, work, mastery and competitiveness. Each questionnaire item is rated on a 5-point Likert scale (1=completely disagree to $5=$ completely agree).In the present study, only the last three subscales were used.

The other questionnaire used in this study was an adapted version for basketball of the Deliberate Practice Motivation Questionnaire (DPMQ -(Gonçalves et al., 2011), originally designed for chess (de Bruin, Rikers, \& Schmidt, 2007). Two dimensions of deliberate practice are considered: will to compete and will to excel. The 18 items were rated in a 5-point Likert scale ( $1=$ completely disagree, $5=$ completely agree). The questionnaire showed good reliability in previous studies (Gonçalves et al., 2011).

\section{Statistical analysis}

Descriptive statistics for chronological age, anthropometric dimensions, estimated age at PHV, functional capacities, and motivation for achievement, competitiveness and deliberate practice were calculated. Subsequently, a series of multilevel linear regression models were fitted to explore the players' body dimensions, functional capacities, 
achievement motivation dimensions and motivation for deliberate practice by maturity status, as well as examining the influence of age. We assumed players (level-1) nested by somatic maturity status category (level-2). A null model, the simplest two level model which includes only the random parameters, was used initially to measure the proportion of total variance which fell between-maturity status (i.e., variance partition coefficient). Given the range of chronological age in the present sample, and variation in age within each somatic maturity status category, we added chronological age of the players (centred at the grand mean) to the null models (allowing for the intercept to vary randomly at both level-1 and level-2).

In the final step of the analysis, we added Line Drill test and Yo-Yo IR1 scores to the multilevel regressions as fixed effects separately, to explore the relationships between motivation for achievement dimensions and deliberate practice with functional capacities. We considered allometric scaling to account for the influence of body size on the interpretation of functional capacities (Nevill, Ramsbottom, \& Williams, 1992). Multilevel regression models and single level regressions, when appropriate, were explored using "nlme" package (Pinheiro \& Bates, 2000), available as a package in the R statistical language (http://cran.r-project.org).

\section{RESULTS}

The descriptive statistics of youth basketball players for the total sample and grouped by maturity status are summarized in Table 1. Variance partition coefficients derived from multilevel null models (i.e., variance partition coefficient $>0.05$ ) indicate a significant variation by maturity status for body dimensions, functional capacities indicators, mastery and will to excel. Also, variance partition coefficient values suggest that the magnitude of differences between players grouped by maturity status were moderate to large for the 
body dimensions and functional capacities, and moderate at best for the psychological variables (Tymms, 2004).

[Table 1 near here]

Table 2 summarizes the multilevel models where chronological age was added as a fixed explanatory variable. For the model with body dimensions as dependent variables, the ranges of $95 \%$ confidence interval for the fixed effects for chronological age indicate that there was no significant independent influence of age on body dimensions, controlling for maturity status category at level-2. Considering the functional capacities variables as dependent variables, the ranges of $95 \%$ confidence interval for the fixed effects for chronological age indicate that there was a significant independent influence of age on both functional capacities indicators. Random effects estimates for the Line Drill test indicate that significant, between-maturity status category variance was present after aligning for chronological age. As for the Yo-Yo IR1, the 95\% confidence intervals were too large and unreliable implying that no significant variance was present at level 2 , meaning that no differences between players grouped by maturity status emerged when chronological age was considered as a fixed explanatory variable.

Adopting a single level analysis, chronological age had a significant effect on mastery and will to excel variables. Considering the variability of age between maturity status categories (see Table 1) we explored if aligning for chronological age could account for between-maturity status variation at level-2 in all achievement motivation and deliberate practice motivation dimensions. The resulting multilevel models indicate that between-maturity status variation at level-2 was indeed independent of chronological age for all psychological variables. 
[Table 1 near here]

The body size exponents resulting from allometric scaling of functional capacities were as follows: stature as independent variable -0.39 (95\% CI $-0.14--0.65)$ and 2.72 (95\% CI 1.63 - 3.80) for Line Drill test and Yo-Yo IR1, respectively; body mass as independent variable -0.09 (95\% CI -0.02- -0.17) and 0.61 (95\% CI 0.25 - 0.97) for Line Drill test and Yo-Yo IR1, respectively. Note that negative allometric exponents for the Line Drill test were apparent as lower time on a running test indicates a better performance. The multilevel linear regressions showed no significant relationship between motivation dimensions with both the Line Drill test and Yo-Yo IR1, as well as when partitioning the influence of body dimensions of functional capacities.

\section{DISCUSSION}

Studies examining the relations between biological maturity status and young athletes' psychological characteristics are sparse (Cumming, Battista, Martyn, Ewing, \& Malina, 2006; Monsma, Malina, \& Feltz, 2006). Thus, to our best knowledge, this study is the first to consider maturity-associated variation on motivation for achievement, competitiveness and deliberate practice of youth basketball players.

Limitations of the maturity offset protocol have been discussed (Malina et al., 2006; Moore et al., 2015) and the protocol may not be a sufficiently sensitive indicator of maturity status. These limitations of the method are recognized in the present study, thus it should be noted that a player may have been assigned to the wrong maturity status category. Nevertheless, the standard deviations for age at PHV in this study (see Table 1) were slightly lower than values reported in studies where the protocol was used and reassessed (Mirwald et al., 2002; Moore et al., 2015), and lower than standard deviations 
derived from longitudinal studies which modelled individual stature data (Malina, Bouchard, \& Beunen, 1988). Also, range of estimated age at PHV in the present study was within the ranges for age at PHV reported in studies where the protocol was used and longitudinal data for individual stature records modelled. Thus, the relative accuracy of the adolescent basketball players' maturity status is assumed.

Studies limited to characteristics of groups (aggregate) of individuals in sports sciences are mainly interpreted based on individual-level analysis. On many occasions, however, these analytic decisions may fail to account for influence of aggregation or clusters of individuals within a specific context (e.g., players within their team or club) on the outcome variable (e.g., physiological or psychological response), likely leading to an incomplete understanding of the outcomes in the individuals as well as in populations (Diez-Roux, 2000). In the present study, we assumed players to be clustered in two levels of observation, i.e., player (level-1) nested by somatic maturity status category (level-2). Thus, multilevel regression models enabled the examination of variance components and, in the present study, determine if mean body dimensions, functional capacities, achievement motivation dimensions and motivation for deliberate practice scores vary notably by maturity status. Furthermore, the nonzero variance partition coefficients observed (see Table 1) indicates that procedures such as 'ordinary least squares' used, for example, in multiple regression, would be inaccurate to explore the present data and could lead to incorrect inferences (Goldstein, 2011).

Variation in body dimensions associated with contrasting maturity status, considering chronological age alignment, in the youth basketball players in the present study was similar to that for basketball adolescents (Carvalho et al., 2013; Carvalho, Silva, Figueiredo, Gonçalves, Philippaerts, et al., 2011; Silva, Figueiredo, Carvalho, \& Malina, 2008) and higher to that for adolescent males in general (Malina, Bouchard, \& 
Bar-Or, 2004). These observations are consistent with the importance placed on body size, stature in particular, to selection in youth basketball (Drinkwater, Pyne, \& McKenna, 2008). Coaches may tend to overlook boys late in biological maturity that may be at a slower growth rate than those advanced in biological maturity status that are taller, heavier, stronger and faster (Carvalho, Silva, Figueiredo, Gonçalves, Philippaerts, et al., 2011; Carvalho et al., 2012).

Performance in the Line Drill test is based on a maximal short duration running effort ( $\sim 30 \mathrm{~s})$ containing seven changes of direction within a regular basketball court. Thus, the protocol has an important agility component, and appears to be sensitive to distinguish adolescent basketball players’ performance (Carvalho, Silva, Figueiredo, Gonçalves, Castagna, et al., 2011). It is notable that players with contrasting maturity status differed substantially in the Line Drill test performance. This trend continued to be present when variation in age within each maturity status category and body dimensions (no significant influence of body dimensions, results not shown) were considered in the multilevel models. The present study results are consistent with observations in shortterm maximal performance among adolescent athletes (Buchheit et al., 2014; Carvalho, Silva, Figueiredo, Gonçalves, Castagna, et al., 2011; Carvalho, Silva, Figueiredo, Gonçalves, Philippaerts, et al., 2011; Mendez-Villanueva et al., 2010) and adolescent males in general (Lefevre, Beunen, Steens, Claessens, \& Renson, 1990) of contrasting maturity status, allowing for variation in protocols and instruments. Furthermore, within each maturity status category, age had an independent influence on Line Drill test performance. These observations imply that chronological age per se, pubertal growth in muscle mass and neuromuscular development and, possibly, the accumulated effects of training may contribute to the variation in results (Carvalho, Silva, Figueiredo, Gonçalves, Castagna, et al., 2011). 
Variation by maturity status group in intermittent endurance performance was explained by chronological age per se. These observations concur with recent longitudinal data in adolescent soccer players (Carvalho et al., 2014; Deprez et al., 2014), but contrast with longitudinal observations of male adolescents in general (Beunen et al., 2002; Welsman \& Armstrong, 2000), among whom maturity status influences maximal oxygen consumption only after adjusting for age and body dimensions. Additionally, the size exponents derived from the allometric scaling are consistent with observations in samples of adolescent basketball players and lower than those in studies of young athletes (Cunha et al., 2011; Eisenmann, Pivarnik, \& Malina, 2001). Thus, in the present study, the older adolescent basketball players had better intermittent endurance performance, probably implying contributions of both changes in active muscle mass due to pubertal and higher exposition to training with age.

The mean values of will to excel and will to compete are comparable to those of adolescent male athletes engaged in club, professional club and elite level contexts (Gonçalves, Diogo, \& Carvalho, 2014). Both achievement motivation and motivation for deliberate practice mean values in the present study were consistently higher than those of elite adolescent chess players (de Bruin et al., 2007). We observed a trend for high values in work, mastery, and will to excel, and lower, but still positive, values for competitiveness.

Early adolescent players, within the range of the present study, are frequently exposed to specialization in basketball programs, where athletes are oriented towards competitive success and exhibit a strong will to become expert players, being exposed to standards of training intensities and volume required by excellence performance (Gonçalves et al., 2011). Thus, the interpretation of achievement motivation and basketball-specific motivation on deliberate practice among adolescent players should 
consider both growth and maturation-related influences on behavioural changes with pubertal development. The results in the present study showed an influence of estimated maturity status on mastery and will to excel indicators.

Furthermore, when aligning chronological age within maturity status categories, there is a substantial between-player variation in mastery, competitiveness and will to excel associated with contrasting maturity in the young basketball players of the present sample. The present findings indicate that attaining a biological maturation milestone may be relevant to understand motivation for achievement and deliberate practice in adolescent basketball players.

Additionally, these results may help to interpret previous observations of achievement variables and motivation in elite adolescent athletes (Elferink-Gemser et al., 2007; Gonçalves et al., 2011). Particularly, observations in under 16 basketball players showing that will to excel was the main predictor identified to classify players by competitive level (Gonçalves et al., 2011). This should be interpreted considering that players in these contexts are highly selected and tend to be advanced in maturity status (Carvalho, Silva, Figueiredo, Gonçalves, Philippaerts, et al., 2011; Malina, 1994).

By contrast, no trend of association was observed between achievement motivation and motivation on deliberate practice with functional performance, even when partitioning the influence of maturity status, chronological age and body dimensions. These observations highlight the importance of considering behavioural differences associated with variation in maturity status in adolescent boys (Jones, 1949; Jones, 1965). Moreover, when attempts are made to predict potential performance of young adolescents engaged in talent identification and development programs in basketball. Observations in the present study add to the claims that comprehensive and holistic approaches are needed to understand the factors underpinning both successful progression along the sport's 
talent pathway as well those that may negatively influence the development within the sport, possibly leading to negative consequences for the individuals (MacNamara \& Collins, 2015).

The apparent dissociation between sport performance and motivation variables may suggest that performance is a result of the body capabilities, maturity status and accumulated training. Interestingly, a targeted individual orientation to perform seems to be absent. Of course, age-related biological, behavioural and social changes experienced during adolescence can all impact on motivation for achievement and competitiveness, and functional performance. Thus, the results of the present study add to the need to consider positive and reinforcing coherent environments (Martindale, Collins, \& Daubney, 2005), with appropriate conduct and performance standards, to promote the appropriate development of functional performance and behavioural characteristics; implicitly shaping players', parents' and coaches' expectations and practices. For the present, the comparative independence of motivation to other key variables is worthy of both note and action. It seems that, independent of performance, psychological variables remain as a consistent intra-individual trend which may be more predictive, or even causative of future progress. Relationships between these 'driver' variables and maturation are also important, making it necessary for coaches to tailor their approaches to fit the maturation level (rather than the chronological age) of each player. In short, one size definitely doesn't fit all!

In summary, a significant variation by maturity status for body size, functional capacities indicators, mastery and will to excel was observed. When considering the variation in chronological age within contrasting maturity status categories, an influence of estimated maturity age for competitiveness was also apparent. No relationship was observed between psychological variables and functional capacities indicators. Thus, 
growth-related changes are relevant to understand players' motivations for achievement, competitiveness and deliberate practice and should be of interest to those involved in the identification, selection and development of youth basketball players, making the training environment a true living laboratory.

\section{Acknowledgements}

The first author was supported by a grant from the Coordenação de Aperfeiçoamento de Pessoal de Nível Superior [PNPD/CAPES/2013]. The patience and cooperation of the young athletes, coaches and parents is acknowledged by the authors.

\section{References}

Abbott, A., Button, C., Pepping, G. J., \& Collins, D. (2005). Unnatural selection: talent identification and development in sport. Nonlinear Dynamics Psychol Life Sci, 9(1), 6188

Bailey, R., Collins, D., Ford, P., MacNamara, A., Toms, M., \& Pearce, G. (2010). Participant development in sport: an academic review. https://www.sportscoachuk.org/sites/default/files/Participant-Development-Lit-

Review.pdf.

Baker, J., \& Horton, S. (2004). A review of primary and secondary influences on sport expertise. High Ability Studies, 15(2), 211-228. doi: 10.1080/1359813042000314781

Bangsbo, J. (1994). Fitness training in footbal - a scientific approach. Bangsvaerd: HO Storm.

Bergeron, M. F., Mountjoy, M., Armstrong, N., Chia, M., Cote, J., Emery, C. A., . . Engebretsen, L. (2015). International Olympic Committee consensus statement on youth athletic development. Br J Sports Med, 49(13), 843-851. doi: 10.1136/bjsports-2015-094962 
Beunen, G., Baxter-Jones, A. D., Mirwald, R. L., Thomis, M., Lefevre, J., Malina, R. M., \& Bailey, D. A. (2002). Intraindividual allometric development of aerobic power in 8- to 16-year-old boys. Med Sci Sports Exerc, 34(3), 503-510

Buchheit, M., Mendez-Villanueva, A., Mayer, N., Jullien, H., Marles, A., Bosquet, L., . . . Lambert, P. (2014). Locomotor performance in highly-trained young soccer players: does body size always matter? Int J Sports Med, 35(6), 494-504. doi: 10.1055/s-0033-1353140

Carvalho, H. M., Bidaurrazaga-Letona, I., Lekue, J. A., Amado, M., Figueiredo, A. J., \& Gil, S. M. (2014). Physical growth and changes in intermittent endurance run performance in young male Basque soccer players. Res Sports Med, 22(4), 408-424. doi: $10.1080 / 15438627.2014 .944301$

Carvalho, H. M., Silva, M., Eisenmann, J. C., \& Malina, R. M. (2013). Aerobic fitness, maturation, and training experience in youth basketball. Int J Sports Physiol Perform, $8(4), 428-434$

Carvalho, H. M., Silva, M., Figueiredo, A. J., Goncalves, C. E., Castagna, C., Philippaerts, R. M., \& Malina, R. M. (2011). Cross-validation and reliability of the line-drill test of anaerobic performance in basketball players 14-16 years. J Strength Cond Res, 25(4), 1113-1119. doi: 10.1519/JSC.0b013e3181d09e38

Carvalho, H. M., Silva, M., Figueiredo, A. J., Goncalves, C. E., Philippaerts, R. M., Castagna, C., \& Malina, R. M. (2011). Predictors of maximal short-term power outputs in basketball players 14-16 years. Eur J Appl Physiol, 111(5), 789-796. doi: 10.1007/s00421-010$1703-4$

Carvalho, H. M., Silva, M., Santos, J., Goncalves, R. S., Philippaerts, R., \& Malina, R. (2012). Scaling lower-limb isokinetic strength for biological maturation and body size in adolescent basketball players. Eur J Appl Physiol, 112(8), 2881-2889. doi: $10.1007 / \mathrm{s} 00421-011-2259-7$

Cumming, S. P., Battista, R. A., Martyn, S., Ewing, M. E., \& Malina, R. M. (2006). Estimated maturity status and perceptions of adult autonomy support in youth soccer players. $J$ Sports Sci, 24(10), 1039-1046. doi: 10.1080/02640410500386142 
Cunha, G., Lorenzi, T., Sapata, K., Lopes, A. L., Gaya, A. C., \& Oliveira, A. (2011). Effect of biological maturation on maximal oxygen uptake and ventilatory thresholds in soccer players: an allometric approach. $J$ Sports Sci, 29(10), 1029-1039. doi: $10.1080 / 02640414.2011 .570775$

de Bruin, A. B., Rikers, R. M., \& Schmidt, H. G. (2007). The influence of achievement motivation and chess-specific motivation on deliberate practice. J Sport Exerc Psychol, 29(5), 561583

Deprez, D., Santos, J., Silva, M., Lenoir, M., Philippaerts, R. M., \& Vaeyens, R. (2014). Modeling developmental changes in yo-yo intermittent recovery test level 1 in elite pubertal soccer players. Int J Sports Physiol Perform, 9(6), 1006-1012. doi: 10.1123/ijspp.2013-0368

Diez-Roux, A. V. (2000). Multilevel analysis in public health research. Annu Rev Public Health, 21, 171-192. doi: 10.1146/annurev.publhealth.21.1.171

Diogo, F., \& Goncalves, C. E. (2014). The path to expertise in youth sport: using a retrospective interview in three different competitive contexts. Percept Mot Skills, 118(2), 317-330. doi: $10.2466 / 30.10 . P M S .118 k 18 w 2$

Drinkwater, E. J., Pyne, D. B., \& McKenna, M. J. (2008). Design and interpretation of anthropometric and fitness testing of basketball players. Sports Med, 38(7), 565-578

Eisenmann, J. C., Pivarnik, J. M., \& Malina, R. M. (2001). Scaling peak VO2 to body mass in young male and female distance runners. J Appl Physiol (1985), 90(6), 2172-2180

Elferink-Gemser, M. T., Visscher, C., Lemmink, K. A., \& Mulder, T. (2007). Multidimensional performance characteristics and standard of performance in talented youth field hockey players: a longitudinal study. $J$ Sports Sci, 25(4), 481-489. doi: $10.1080 / 02640410600719945$

Elferink-Gemser, M. T., Visscher, C., Lemmink, K. A., \& Mulder, T. W. (2004). Relation between multidimensional performance characteristics and level of performance in talented youth field hockey players. J Sports Sci, 22(11-12), 1053-1063. doi: $10.1080 / 02640410410001729991$

Goldstein, H. (2011). Multilevel statistical models (4th ed.). Chichester, West Sussex: Wiley. 
Gonçalves, C. E., Diogo, F. L., \& Carvalho, H. M. (2014). A multilevel approach to the path to expertise in three different competitive settings. J Sports Sci Med, 13(1), 166-171

Gonçalves, C. E., Rama, L. M., \& Figueiredo, A. J. (2012). Talent identification and specialization in sport: an overview of some unanswered questions. Int J Sports Physiol Perform, 7(4), 390-393

Gonçalves, C. E., Silva, M., Carvalho, H. M., \& Goncalves, A. (2011). Why do they engage in such hard programs? The search for excellence in youth basketball. J Sports Sci Med, $10(3), 458-464$

Harriss, D. J., \& Atkinson, G. (2009). International Journal of Sports Medicine - ethical standards in sport and exercise science research. Int J Sports Med, 30(10), 701-702. doi: 10.1055/s0029-1237378

Jones, H. E. (1949). Motor performance and growth; a developmental study of static dynamometric strength. Berkeley,: Univ. of California Press.

Jones, M. C. (1965). Psychological correlates of somatic development. Child Dev, 36(4), 899-911

Lefevre, J., Beunen, G., Steens, G., Claessens, A., \& Renson, R. (1990). Motor performance during adolescence and age thirty as related to age at peak height velocity. Ann Hum Biol, $17(5), 423-435$

Lohman, T. G., Roche, A. F., \& Martorell, R. (1988). Anthropometric Standardization Reference Manual. Champaign, IL: Human Kinetics

MacNamara, A., \& Collins, D. (2015). Profiling, Exploiting, and Countering Psychological Characteristics in Talent Identification and Development. The Sport Psychologist, 29(1), 73-81. doi: 10.1123/tsp.2014-0021

Malina, R. M. (1994). Physical growth and biological maturation of young athletes. Exerc Sport Sci Rev, 22, 389-433

Malina, R. M., Bouchard, C., \& Bar-Or, O. (2004). Growth, Maturation, and Physical Activity: Human Kinetics.

Malina, R. M., Bouchard, C., \& Beunen, G. (1988). Human growth:selected aspects of current research on well-nourished children. Annu Rev Anthropol, 17, 187-219 
Malina, R. M., Claessens, A. L., Van Aken, K., Thomis, M., Lefevre, J., Philippaerts, R., \& Beunen, G. P. (2006). Maturity offset in gymnasts: application of a prediction equation. Med Sci Sports Exerc, 38(7), 1342-1347. doi: 10.1249/01.mss.0000227321.61964.09

00005768-200607000-00020 [pii]

Martindale, R. J., Collins, D., \& Daubney, J. (2005). Talent Development: A Guide for Practice and Research Within Sport. Quest, 57(4), 353-375. doi: $10.1080 / 00336297.2005 .10491862$

Mendez-Villanueva, A., Buchheit, M., Kuitunen, S., Poon, T. K., Simpson, B., \& Peltola, E. (2010). Is the relationship between sprinting and maximal aerobic speeds in young soccer players affected by maturation? Pediatr Exerc Sci, 22(4), 497-510

Mirwald, R. L., Baxter-Jones, A. D., Bailey, D. A., \& Beunen, G. P. (2002). An assessment of maturity from anthropometric measurements. Med Sci Sports Exerc, 34(4), 689-694

Monsma, E. V., Malina, R. M., \& Feltz, D. L. (2006). Puberty and physical self-perceptions of competitive female figure skaters: an interdisciplinary approach. Res $Q$ Exerc Sport, 77(2), 158-166. doi: 10.1080/02701367.2006.10599350

Moore, S. A., McKay, H. A., Macdonald, H., Nettlefold, L., Baxter-Jones, A. D., Cameron, N., \& Brasher, P. M. (2015). Enhancing a Somatic Maturity Prediction Model. Med Sci Sports Exerc, 47(8), 1755-1764. doi: 10.1249/MSS.0000000000000588

Nevill, A. M., Ramsbottom, R., \& Williams, C. (1992). Scaling physiological measurements for individuals of different body size. Eur J Appl Physiol Occup Physiol, 65(2), 110-117

Pinheiro, J. C., \& Bates, D. M. (2000). Mixed-effects models with S and S-plus. New York: Springer.

Reilly, T., Williams, A. M., Nevill, A., \& Franks, A. (2000). A multidisciplinary approach to talent identification in soccer. $J$ Sports Sci, 18(9), 695-702. doi: $10.1080 / 02640410050120078$

Semenick, D. (1990). TESTS AND MEASUREMENTS: The Line Drill Test. Strength \& Conditioning Journal, 12(2), 47-49 
Sherar, L. B., Cumming, S. P., Eisenmann, J. C., Baxter-Jones, A. D., \& Malina, R. M. (2010). Adolescent biological maturity and physical activity: biology meets behavior. Pediatr Exerc Sci, 22(3), 332-349

Silva, M. J., Figueiredo, A. J., Moreira Carvalho, H., \& Malina, R. M. (2008). Functional capacities and sport-specific skills of 14- to 15-year-old male basketball players: Size and maturity effects. European Journal of Sport Science, 8(5), 277-285. doi: $10.1080 / 17461390802117177$

Spence, J. T., \& Helmreich, R. L. (1983). Achievement-related motives and behaviours. In J. T. Spence (Ed.), Achievement and achievement motives: psychological and sociological approaches (pp. 10-74). San Francisco, CA: W.H. Freeman and Company.

Tymms, P. (2004). Effect sizes in multilevel models. In I. Schagen \& K. Elliot (Eds.), But what does it mean? The use of effect sizes in educational research (pp. 55-66): National Foundation for Educational Research.

Welsman, J. R., \& Armstrong, N. (2000). Longitudinal changes in submaximal oxygen uptake in 11- to 13-year-olds. J Sports Sci, 18(3), 183-189. doi: 10.1080/026404100365081 


\section{Tables}

Table 1. Descriptive statistics (mean and standard deviation) for the total sample and for players in each estimated maturity status category

\begin{tabular}{|c|c|c|c|c|c|}
\hline & $\begin{array}{l}\text { All sample } \\
\mathrm{n}=58\end{array}$ & $\begin{array}{c}\text { Pre-PHV } \\
n=25\end{array}$ & $\begin{array}{c}\text { Circum-PHV } \\
n=18\end{array}$ & $\begin{array}{l}\text { Post-PHV } \\
\text { n }=15\end{array}$ & $\begin{array}{c}\text { Variance partition } \\
\text { coefficient }\end{array}$ \\
\hline Chronological age, yrs & $13.1(1.6)$ & $11.7(0.9)$ & $13.5(0.7)$ & $15.1(0.4)$ & 0.84 \\
\hline Maturity offset, yrs & $-0.93(1.65)$ & $-1.99(0.62)$ & $0.05(0.63)$ & $1.75(0.38)$ & 0.91 \\
\hline Stature, $\mathrm{cm}$ & $167.7(14.8)$ & $153.5(7.9)$ & $173.5(5.3)$ & $184.2(7.3)$ & 0.83 \\
\hline Body mass, $\mathrm{kg}$ & $60.0(17.0)$ & $45.4(9.9)$ & $65.2(12.0)$ & $77.9(8.3)$ & 0.71 \\
\hline Sitting height, cm & $83.5(7.3)$ & $76.5(3.5)$ & $85.8(3.2)$ & $92.2(2.7)$ & 0.86 \\
\hline Line-drill test, $\mathrm{s}$ & $34.99(3.12)$ & $36.30(3.29)$ & $34.21(2.65)$ & $33.56(2.52)$ & 0.16 \\
\hline Yo-Yo IR1, m & $538.3(239.5)$ & $430.9(126.45)$ & $613.1(266.4)$ & $770.7(189.1)$ & 0.40 \\
\hline \multicolumn{6}{|l|}{ Achievement motivation } \\
\hline Work (1- 5) & $4.47(0.50)$ & $4.38(0.57)$ & $4.51(0.48)$ & $4.57(0.42)$ & 0.00 \\
\hline Mastery (1- 5) & $4.18(0.66)$ & $3.82(0.71)$ & $4.51(0.50)$ & $4.38(0.47)$ & 0.26 \\
\hline Competitiveness (1- 5) & $3.64(0.73)$ & $3.49(0.71)$ & $3.86(0.67)$ & $3.63(0.80)$ & 0.02 \\
\hline \multicolumn{6}{|c|}{ Deliberate practice motivation } \\
\hline Will to excel (1- 5) & $4.22(0.80)$ & $4.03(0.78)$ & $4.54(0.61)$ & $4.16(0.96)$ & 0.06 \\
\hline Will to compete (1- 5) & $4.35(0.57)$ & $4.22(0.54)$ & $4.51(0.60)$ & $4.38(0.55)$ & 0.03 \\
\hline
\end{tabular}


Table 2. Multilevel regression models for analysis of covariance (random effect ANCOVA) considering nesting by maturity status (at level-2) and controlling chronological age (grand mean centered at 11.7 years)

\begin{tabular}{|c|c|c|c|c|c|}
\hline & \multicolumn{2}{|c|}{ Fixed effects (95\% confidence intervals) } & \multicolumn{2}{|c|}{ Random effects (95\% confidence intervals) } & \multirow{2}{*}{$\begin{array}{c}\text { Variance partition } \\
\text { coefficient }\end{array}$} \\
\hline & Intercept & Age centered & Level 1 standard deviation & Level 2 standard deviation & \\
\hline Stature & 150.9 (153.9 to 186.2$)$ & $1.1(-1.5$ to 3.6$)$ & $7.0(5.8$ to 8.5$)$ & $13.9(4.9$ to 39.3$)$ & 0.79 \\
\hline Body mass & $62.4(45.5$ to 79.3$)$ & $1.3(-2.4$ to 4.9$)$ & $10.4(8.6$ to 12.5$)$ & $14.4(4.7$ to 43.4$)$ & 0.66 \\
\hline Sitting height & $84.7(76.5$ to 92.8$)$ & $0.5(-0.6$ to 1.7$)$ & $3.2(2.7$ to 3.9$)$ & $7.0(2.5$ to 19.6$)$ & 0.82 \\
\hline Line-drill test & 35.4 (31.7 to 39.0$)$ & $-2.6(-3.4$ to -1.8$)$ & $2.1(1.7$ to 2.6$)$ & $3.1(1.0$ to 9.4$)$ & 0.68 \\
\hline Yo-Yo IR1 & $566.5(518.1$ to 614.8$)$ & $111.9(78.6$ to 145.2$)$ & $177.2(146.5$ to 214.3$)$ & $2.6^{\mathrm{a}}$ & 0.00 \\
\hline \multicolumn{6}{|c|}{ Achievement motivation } \\
\hline Work & $4.47(4.34$ to 4.60$)$ & $0.04(-0.05$ to 0.13$)$ & $0.51(0.42$ to 0.61$)$ & $0.00^{\mathrm{a}}$ & 0.00 \\
\hline Mastery & $4.22(3.79$ to 4.65$)$ & $0.03(-0.15$ to 0.21$)$ & $0.60(0.50$ to 0.72$)$ & $0.34(0.08$ to 1.39$)$ & 0.24 \\
\hline Competitiveness & $3.66(3.38$ to 3.93$)$ & $0.00(-0.16$ to 0.16$)$ & $0.72(0.60$ to 0.87$)$ & $0.17(0.01$ to 2.05$)$ & 0.05 \\
\hline \multicolumn{6}{|c|}{ Deliberate practice motivation } \\
\hline Will to excel & $4.24(3.86$ to 4.63$)$ & $-0.02(-0.22$ to 0.18$)$ & $0.78(0.65$ to 0.93$)$ & $0.28(0.05$ to 1.42$)$ & 0.11 \\
\hline Will to compete & $4.35(4.18$ to 4.53$)$ & 0.04 (-0.06 to 0.15$)$ & $0.56(0.47$ to 0.68$)$ & $0.08(0.00$ to 5.43$)$ & 0.02 \\
\hline
\end{tabular}

$\bar{a}$ The 95\% confidence intervals were too large and unreliable implying that no significant variance was present at level-2, which means no differences between players grouped by maturity status when chronological age was considered as a fixed explanatory variable. 